\author{
Е.А. Каминская
}

\title{
АНТРОПОЛОГИЧЕСКИЕ ИЗМЕРЕНИЯ КУЛЬТУРНЫХ СМЫСЛОВ ТРАДИЦИОННОГО ФОЛЬКЛОРА
}

Аннотация. Предметом исследования являются тексты традиционного фольклора в их антропологических аспектах, раскрывающих бытийственно-смысловые, символически-смысловые, процессуально-смысловые стороны. Особое внимание уделяется анализу специфического положения традиционного фольклора в истории культуры, в современном культурном пространстве, описанию различных точек зрения на данную проблему, подтверждающих тенденцию усложнения социокультурного бытия. Приводится аргументация того, что традиционный фольклор для актуальной культуры представляет собой весьма противоречивое, сложное, многоаспектное, укоренённое в её истории явление. Важнейшая задача статьи: с помощью экземплифрикативного подхода доказать полисимволическое наполнение фольклорных действ и возможность их актуализации в условиях современной культуры. Автор указывает на необходимость использования методов культурной антропологии. В статье раскрываются культурные смыслы традиционного фольклора через призму антропологических констатаций и описания его символического звучания. Предметно показаны символические репрезентации сущностных оснований традиционного фольклора, обнаруживающие его культурные смыслы в конкретном обрядовом действе «Расплетание косы». Тем самым подтверждается плодотворность анализа традиционного фольклора с позиций онтически-смыслового; символически-смыслового; процессуально-смыслового аспекта.

Ключевые слова: традиционный фольклор, традиционная культура, традиция, онтически-смысловые аспекты, символически-смысловые аспекты, процессуально-смысловые аспекты, культурные смыслы, символы, обряды, инициации.

Abstract. The subject of this research is the texts of traditional folklore in its anthropological aspects, which reveal ontological-conceptual, symbolic-conceptual, and procedural-conceptual sides. Special attention is given to the analysis of specific position of the traditional folklore in the history of culture and contemporary cultural space, as well as to the description of various points of view upon this problem, which confirm the tendency of complication of the sociocultural existence. The author provides argumentation that the traditional folklore with regards to the modern culture, represents a rather controversial, complex, multi-aspect, and accelerated in its history phenomenon. The major goal of the article consists in the following: to prove the polysymbolic content of folklore actions and possibility of their realization under the conditions of modern culture, using the exemplificative approach. The author underlines the importance of using the methods of cultural anthropology. This article reveals the cultural concepts of the traditional folklore through the prism of anthropological constants and description of its symbolic sound.

Key words: Procedural-conceptual aspects, Symbolic-conceptual aspects, Ontological-conceptual aspects, Tradition, Traditional culture, Traditional folklore, Cultural concepts, Symbols, Customs, Initiations.

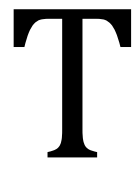
радиционный фольклор в контексте современной культуры представляет собой достаточно противоречивое явление. С одной стороны, нередко встречаются мнения о том, что «Традиционная культура и фольклор сегодня - это своего рода легендарная Атлантида, которая на наших глазах уходит под воду и важно остановить или, во всяком случае, зафиксировать процесс её пока ещё живого бытования» [1]; «факт угасания традиционной культуры неоспорим» $[2$, c. 204]; «традиционная культура уже фактически утратила свою прежнюю жизнеобеспечивающую функцию», «современная традиционная культура $<$...> превратилась лишь в элемент образа жизни, в рамках которого в некоторых, символически наиболее значимых формах, люди стараются придерживаться традиционных образцов. Т.е. традиционная культура стала <..> демонстративной культурной манифестацией» [3], «иссякает источник народной <...> культуры, поскольку неумолимо иссякает сама 
аутентичная среда её бытования» [4]. Однако, вслед за Д. Варламовым трактуя традицию, лежащую в основе традиционной культуры, как «специфический феномен культуры, лежащий в фундаменте культуры в целом» [5, с. 15], мы не можем признать факт её безоговорочного исчезновения из культуры. Иначе нам пришлось бы говорить о потере одного из её фундирующих оснований.

Одновременно манифестируется пиететное отношение к ней, необходимость сохранения традиций в широком смысле слова и, с одной стороны, явлений, в той или иной мере на эти традиции опирающихся, а с другой стороны, явлений, которые смогли бы в различной степени эти традиции поддержать, сохранить, развить. Например, В.А. Куц, анализируя культурную идентичность как способ реализации защитных функций культуры, указывает: «Идентичность, прежде всего, необходима для сохранения и поддержания традиционных ценностей (выделено мною - Е.К.) и налаживания диалога между различными культурами, который зависит от признания и более полного восприятия культурного многообразия» [6].

Мы не случайно привели цитаты относительно степени жизнеспособности традиционной культуры в современности, поскольку традиционный фольклор представляет одно из ярких, но специфичных явлений этого же порядка. Он выступает как сложный полифоничный, полисмысловой феномен, способствующий идентификации людей в социуме за счёт их интеграции, поддерживающий и развивающий разнообразные коммуникативные связи внутри общества. Одновременно сам традиционный фольклор подвержен влиянию со стороны актуальной культуры, хотя это влияние может быть не явным и проявляться опосредованным образом. Например, появление нового типа коммуникации (сети Интернет), которая получила условное название «устно-письменной», послужило толчком для развития и интернет-фольклора, в том числе понимаемого и как существование фольклора в интернете. Его достаточно широкую популярность, как правило, объясняют высокой скоростью и большим масштабом распространения, возможностью анонимного, вариантного, спонтанного существования и развития, созвучием архаичности (трактуемой, скорее, как константность) и современных культурных практик. Одновременно с этим возник и так называемый «фольклор про Интернет»: про социальные сети, компьютерщиков, сисадминов, чаты и пр. Конечно, большинство его текстов правильней было бы отнести или к пост-фольклору, или к текстам, пограничным между фольклором и пост-фольклором (или нео-фольклором в терми- нологии В.П. Аникина). Но, несомненно, они входят в такое явление как современная фольклорная культура, фундаментом которой выступает традиционный фольклор. Ещё пример - так называемое «осовременивание» образцов традиционного фольклора: введение понятных и известных персонажей, использование новых доступных материалов, изменение среды бытования, варьирование художественных средств. Приведём несколько примеров. Так, в традиционной считалочке «Вышел месяц из тумана...» изменяется основной персонаж - «месяц» на варианты - «ёжик» (отсыл к мультфильму «Ёжик в тумане»), «Децл» (российский репер); «ножик» на современные предметы (в соответствии с временем их появления») - «пейджер», «плеер» и т.д. Приведём пример осовремененной пословицы «Больше дела, меньше снов» (вместо традиционной «больше дела - меньше слов»), в которой подчёркивается актуальное отношение к всё более ускоряющемуся темпу жизни, в котором не остаётся времени на личное, вплоть до самого необходимого. Стоит указать и на многочисленные преобразования музыкального фольклора и в эстрадном, и в фолк-рок, и этно-джазовом, и фолкпанк, и фолк-металл, и мн. др. стилях.

Всё это - творческая, формообразующая и смыслонесущая адаптация и актуализация традиционных текстов (в широком смысле слова). Конечно, подчеркнём это ещё раз, такие произведения занимают промежуточное отношение между, собственно, традиционным фольклором, постфольклором, фольклоризмом в различных сочленениях. Но они являются показательными примерами того, как традиционный фольклор способен адаптироваться к условиям современности, и как актуальные культурные практики могут оказывать на него влияние, одновременно способствуя его сохранению, воссозданию, развитию.

Такая межкультурная коммуникация между традиционным фольклором и иными актуальными для того или иного времени явлениями культуры, а также между фольклорными комплексами различных народов происходила на протяжении всей истории культуры. Например, после заселения Урала русскоговорящими людьми, произошло слияние русской, украинской, тюркской культур, которое проявило себя в некоторых фольклорных традициях, конечно же, имеющих локальные отличия, таких как костюмы жениха и невесты на свадьбе, обычаи платить калым, покрывание столов и лавок кошмою и пр. В некоторых случаях достаточно сложно без специального анализа выделить элементы той или иной культуры в конкретном фольклорном тексте (в широком смысле слова). 
При этом следует помнить, что само положение традиционного фольклора в разных культурно-исторических контекстах было различным, причём с течением времени ситуация становилась всё более неопределённой, соответствуя неоспоримой тенденции динамизации и усложнения социокультурного бытия. Достаточно указать на период средневековья, ярко проявивший неоднозначное отношение к фольклору. С одной стороны, его резкая критика как явления, обеспечивающего языческие культурные практики, с другой - опора на фольклорные мотивы, их включение и некоторое слияние, в том числе, в монотеистические обрядовые практики. И далее, вплоть до времени романтизма, за народной культурой в целом, и фольклора как её части, чаще всего, закреплялось положение «старины», «архаики», «отсталости». Одновременно, предпринимались попытки идеализации народного быта, например, у французских просветителей, осуществлялся поиск в фольклоре новых тем, сюжетов, образов, т.е. его активное использование для нужд, как правило, авторского творчества, соответствующего социокультурному настрою, охватывающему, в том числе, просвещенные группы общества того времени. В целом и XX в. демонстрировал неоднозначное отношение к традиционному фольклору: его принижение, примитивизация, с одной стороны, активное использование (например, в коллективах художественной самодеятельности), с другой, установку на сохранение в собирательско-исследовательской деятельности, с третьей, применение его форм, методов, стилистических приемов (например, в так называемом советском фольклоре), с четвёртой. И даже этими четырьмя вариантами не ограничивается показ спектра отношений к нему.

Разумеется, такое сложное положение традиционного фольклора порождает его высокую проблематичность существования и осмысления рядом разных дисциплин, таких, как философия, этнология, лингвистика, психология, педагогика, культурология и пр. При этом, как отмечает Г.Р. Консон с опорой на труды К. Жабинского: «В системе культурологии <...> интегрируется ряд наук: культурфилософия, культурная и социальная антропология, социология культуры, этнология, семантика и семиотика, синергетика, культурпсихология, история культуры, филология» [7, с. 162-163]. Тем самым именно культурология закономерно принимает в данном видении роль универсальной дисциплинарной области. Исходя из этого контекста, нам представляется, что существенным в проблематике понимания и анализа культурных смыслов традиционного фольклора является взгляд с позиций культурной антропологии, с которых открываются особые аспекты смыслового звучания текстов традиционного фольклора. Причём они значимы не только для общностей традиционального типа, к которым часто апеллируют «классические» антропологи, но и для самых актуальных ситуаций современных культурных коллизий.

В самом общем виде можно выделить три основных аспекта, представляющих смысловое поле фольклора в антропологическом видении: онтически (бытийственно)-смысловой; символическисмысловой; процессуально-смысловой.

Онтически-смысловой аспект обусловлен интенционально-практическим мировоззрением, которое в сознании образует некий смыслообраз существования бытийственных моментов жизни. Они воплощаются в архетипы и символы (символически-смысловой аспект) и порождают определённую мотивацию к мысленному, ритуальному, символическому, импульсивному и пр. действию (процессуально-смысловой аспект). Тем самым образуется некое триединство смыслов от первичной заданности мировоззрения через символизм к тому или иному виду культурных практик.

Мы не претендуем на полное рассмотрение означенной проблемы, а очертим лишь некоторые аспекты антропологической оптики подхода к традиционному фольклору. Этого будет достаточно, на наш взгляд, чтобы представить его в свете антропологических установок. Сказанное дополняет картину актуального функционирования традиционного фольклора в его укоренённости в истории культуры.

Чтобы представить указанные аспекты предметно, целесообразно опереться на тексты, в которых они звучат наиболее отчётливо. Прежде всего, речь идёт о фундаментальных основах подобной аспектации, и в этом случае наиболее убедительной нам представляется позиция П.С. Гуревича. Он пишет: «Выявление специфики культуры невозможно без антропологических констатаций и без выявления сакрального смысла человеческой деятельности. Следовательно, можно определить культуру как феномен, рождённый незавершённостью, открытостью человечной природы, развёртыванием творческой деятельности человека, направленной на поиск сакрального смысла бытия» [8, c. 37]. Традиционный фольклор, выступающий как одно из значимых в этом смысле явлений культуры, с точки зрения такого подхода сам является незавершённым, процессуально-пролонгированным феноменом, несущим сакральные и профанные культурные смыслы, продолжающим своё творческое существование и актуальное развитие в современности. Его определение как народного 
творчества, которое можно встретить у достаточного количества учёных-фольклористов [9; $10 ; 11$; 12], хоть и не является окончательно завершённым, но подчёркивает его культуротворческое начало как важнейшую сущностную характеристику. Условно (в рамках данной статьи) обозначив фольклор как совокупное проявление и результаты народного творчества, мы лишь кратко скажем, что само «фольклорное творчество» можно, с достаточной степенью схематичности, представить как специфичное сочетание внешних и внутренних параметров. К внешним параметрам, на наш взгляд, следует отнести проявления творчества в исторической динамике развития самого традиционного фольклора через усложнение его родо-видо-жанровой палитры, порождение его новых текстов, видоизменение форм бытования и пр. Внутренние параметры творчества связаны с его живым существованием в синкретичной триаде «создание (воссоздание) - исполнение (воспроизведение) восприятие». Таким образом, подчеркнём ещё раз, традиционный фольклор предстаёт как процесс и результат творческой деятельности человека. В нём воплощаются глубинные культурные смыслы, способные придать самой культуре значимость, весомость, раскрыть её корневые основы.

При этом следует отметить, что вектор этого творческого движения, парадоксальным образом сочетающего кругооборот вечного возвращения к глубинным ценностным основаниям народной ментальности и спиралевидную траекторию подъёма к самым актуальным коллизиям современного бытия, целенаправлен именно к тем сакральным смыслам, о которых и говорит П.С. Гуревич [8]. Тем самым предметно воплощается его социокультурная бытийственность. И прежде всего эти аспекты проявляются (и являют себя) в символических репрезентациях своих сущностных оснований.

Не вызывает сомнения символическое содержание традиционного фольклора. Принято говорить о его символике цвета, костюма, текста, действа и пр. По мнению Э.М. Спировой: «Многие отечественные философы указывают на бесконечность символа, на возможность его глубинного толкования. <..> Символ же допускает множество толкований, больше, нежели, скажем, слово или знак» [13, с. 39]. «Символ как раз и выражает нерасторжимую связь биологического организма с непостижимым, с тем, что нуждается в разгадке, в нетривиальном обнаружении человеческого смысла (выделено мною - E.К.), человеческой сути. Это как раз и позволяет через понятие символа проникать в глубины философско-антропологической рефлексии» [13, с. 40]. В связи с указанной трактовкой самого символа, символическое наполнение и толкование текстов традиционного фольклора помогает раскрыть сущность глубинных культурных смыслов, в нём заложенных. Работ, посвящённых семиотическим, в том числе символическим аспектам традиционной культуры и традиционного фольклора достаточно. Следует отметить широкое освещение вопросов символики декоративно-прикладного творчества/ искусства (не будет в рамках данной статьи обозначать различия между данными и терминами, и явлениями), образно-символическим наполнением русского зодчества во всём многообразии проявлений (художественно-образно-символический строй крестьянского жилища, символика вышивки, знаково-символические функции народного костюма и т.п.). Достаточное количество работ раскрывают вопросы семиотического звучания текстов традиционного фольклора, их формульности, кодовости. Стоит просто напомнить о некоторых композиционных приёмах его (фольклора) произведений, прежде всего о поэтическом параллелизме - соотнесении образов природы с образами и чувствами людей. Например, лебёдушка символизирует девушку, селезень - парня, непогода - сильные переживания, цветущий луг (сад) - радость и счастье. Но эти же антропоморфные образы могут быть выражены и с помощью других образов-символов, таких как берёзка (девушка), вьюн (парень). Этот простейший пример доказывает ранее высказанную мысль о бесконечности символов, возможности их полисемантического наполнения и многогранности расшифровки.

В таком понимании именно символическое звучание культурных смыслов традиционного фольклора обретает отчётливо выраженную перформативность (реальную действенность), большое количество примеров чему приводить, как представляется, нет необходимости в силу их очевидного множества и разнообразия.

Тем не менее, позволим себе описать хотя бы один из них, чтобы наиболее предметно показать антропологические аспекты культурных смыслов традиционного фольклора. Например, действо расплетания косы в свадебной обрядовости присутствует во всех региональных вариантах и типах традиционной свадьбы. Стоит иметь в виду, что речь идёт о действенном воплощении фольклорных образов, сюжетов, стилистик и смыслов. При всех вариантах его свершения имеет определённое значение: изменение девичьей прически на женскую. Но это лишь визуально воплощённая сторона обряда. Его же символический смысл более глубок: расплетание косы не просто репрезентирует обстоятельства смены социального статуса, т.е. 
имеет отношение к ситуациям, связанным с существенными трансформациями социокультурного статуса человека в контексте и повседневной, и событийной сторон культуры. Это фольклорное действо относится и к одному из инициационных обрядовых действ, связанных с моментами социокультурного рождения - перерождения. Подтверждением тому можно считать и некоторые другие обрядовые действия с волосяным покровом в момент ключевых событий жизни: запрет на обрезание волос до семи лет у славян, завязывание пояска из нитей (шерстяных - чаще всего), пуповины, волос матери и отца вокруг новорожденного ребёнка, срезание пучка волос во время крещения и т.д. Волосы ассоциировались с чудодейственной силой владельца (стоит лишь упомянуть известнейший миф «Самсон и Далила»); они могли символизировать связь между миром живых и потусторонними мирами (напомним о значении волос для шаманов), использовались в различных магических ритуалах. Кроме того, с ними связано достаточно большое количество примет и поверий, в том числе и актуальных, если вспомнить, например, значение «хаера» у хиппи. Всё это свидетельствует о том, что к волосяному покрову существовало особое отношение. Поэтому изменение прически во время свадебного обряда - особый символический ритуал. Как правило, он осуществлялся или ночью или рано утром, т.е. в «переходное» время, что уже само по себе символизировало особый промежуточный статус невесты: не просто между девичеством и замужеством, но и между миром живых и мёртвых. В отношении того, кто расплетает косу невесте, мнения исследователей расходятся, что вполне объяснимо этнолокальными вариантами обряда. Это может быть и её брат, и отец, и замужние женщины, и крестная (после принятия христианства), и др. Расплетание косы мужчинами (отцом, братом) могло символизировать будущую «другую» жизнь невесты в доме мужа (как бы предвосхищая обряды расчёсывания волос жены мужем), потерю воли и подчинение мужчине как главе семьи. Участие в обрядах замужних женщин должно было придать особый социальный статус невесте (условное «официальное» разрешение на контакты с ними, запрет на контакты с незамужними девушками), передачу ими своих «женских сил» и функций, связанных, прежде всего, с деторождением. Расплетание косы всегда сопровождалось исполнением ритуальных «плачей» и причитаний (сопоставимыми с плачами и причитаниями во время похорон, рекрутских проводов, т.е., опять-таки, инициационными обрядами), что ещё раз подчёркивает его особые культурные смыслы и значения.
Этот пример очень показателен. Во-первых, он представляет собой достаточно типичный обряд, одновременно качественно характеризующий контекстуальную среду в целом. Во-вторых, он содержательно и функционально значим для этой среды. В-третьих, культурные смыслы и значения выражены в нём достаточно отчётливо. Иначе говоря, означенные выше в теоретическом изложении аспекты представлены в данном примере достаточно наглядно. Триединство их онтически (бытийственно)-смыслового, символически-смыслового и процессуально-смыслового аспектов выражены достаточно чётко. Бытийственный компонент раскрывается на уровне «прикладного» назначения обряда, символический показывает многообразие возможностей расшифровок самих символов (изменение социального статуса, магические действия с волосами, рождение-перерождение и пр.), процессуальный подчёркивает незавершённость данного действия и всего цикла обрядов, их циклическую повторяемость, необходимость и вероятность продолжения и т.д.

В нём не только отражается жизнеспособность традиционной культуры в современности, но и смысловое поле конкретного фольклорного действа. Несмотря на его архаические корни, он не только органично репрезентует бытовое, социальное, символически-сакральное значение фольклорного действа, но и позволяет увидеть их глубинные культурные смыслы. Тем самым не только подтверждается неоспоримое значение в традиционной культуре такого сложного и противоречивого явления, как фольклор, но и, как мы уже отметили, архаическое свойство его смыслового поля к межкультурной коммуникации с иными актуальными для того или иного времени явлениями культуры. В том числе и в таких отмеченных нами антропологических аспектах, как онтически (бытийственно)-смысловом; символически-смысловом и процессуально-смысловом, что помогает выявлять и раскрывать заложенную в них сущность глубинных культурных смыслов.

Или другой пример, гадания, в той или иной степени присущие календарно-земледельческим и семейно-бытовым обрядам (гадания на зимних святках, на Троицу, на Ивана Купалу и мн. др.). В них ярко проявляет себя символически-смысловой и процессуально-смысловой аспект. В гаданиях и используемые предметы, если таковые имеются, и сами действия, и их результаты трактуются не в прямом значении, а именно как символы, требующие дополнительной расшифровки, толкования, особых (магических, семиотических, символических знаний). Одновременно, в гаданиях как бы со- 
единяется прошлое (напр., обращение к умершим предкам, использование традиционно (из глубины веков) устоявшихся предметов и приёмов и пр.) - настоящее (время самого гадания) - будущее (предвосхищение, составление своеобразной «программы»). В тоже время, возможно, бытийственносмысловой аспект может показаться отошедшим на второй план. Однако это не так. Ведь гадания имели несомненное практическое назначение, среди других механизмов способствовали обеспечению дальнейшей жизнедеятельности социума. Следовательно, культурные смыслы гаданий, раскрываемые в триединстве бытийственного, символического и процессуального аспектов, гораздо шире их значения, предназначения, функций, самих символических структур, ими используемых.

Предвидим возражения о том, что обряды, ритуалы, магические действа - это не фольклор. Однако вряд ли у кого-то возникнет отрицание того, что тексты, их сопровождающие (как словесные, так и музыкальные) - это явления обрядового фольклора, в некоторых случаях (как в части гаданий, например) обеспечивающие сам процесс этого ритуала, обряда, действа. Часть обрядового фольклора вообще не существует вне них, образуя синкретичное единство между, собственно, обрядом и фольклорным текстом [14]. Именно поэтому мы посчитали возможным обратиться к этим примерам.

Однако обратимся к текстам внеобрядового фольклора, дабы избежать отсыла к символикоритуальным обрядовым практикам. Проанализируем, для примера, лирическую песню Челябинской области «Туман яром» $[15$, с. 22$]$ :

\section{Туман яром, туман долыною}

За туманом ничого нэ выдно.

Тилькы выдно дуба зэлэного.

Пид тым дубом крыныця стояла.

В тий крыници дивка воду брала.

Мы видим, что в художественном строе приведённой песни использованы следующие образысимволы: туман, долина, дуб, криница (колодец, источник), вода. Туман - неперсонифицированный образ, соотносящийся с чувствами и переживаниями героя. В данном случае - это символ неопределённого положения девушки и её переживания по данному поводу. Долина в данном контексте может символизировать человеческую жизнь вообще, в частности - жизнь персонажа песни. Это подчёркивается и использованием образов, в той или иной степени связанных с пограничьем: вода и криница. Криница (и в значении колодец, и в значении источник) и вода достаточно часто символизирова- ли переход между мирами: миром живых и миром мёртвых (вспомним реки смерти в древнегреческой, египетской мифологиях; «потопление» идола Перуна в Днепре и в Волхове в Х в., означающее их свержение - смерть и пр.). Одновременно вода - это и очистительный символ. Дуб многие исследователи связывают с образом парня (жениха). Тем самым мы можем расшифровать символику этой песни следующим образом: девушка, находящаяся в момент перехода между мирами (из последующего контекста ясно, что, скорее всего, или в ожидании сватовства, или сразу после него, но до свадьбы) переживает (что вполне естественно) за свою судьбу и будущую жизнь. В этой перспективе ей ещё ничего неизвестно, кроме того, что есть жених (напомним, что в некоторых традициях невесту с женихом могли знакомить уже после венчания или прямо накануне него). Однако она знает, что ей предстоит этот переход и ряд магически-очистительных обрядов. Несмотря на то, что автор сборника отнёс песню к лирическим внеобрядовым песням, возможно, что она исполнялась во время обряда, но не имела конкретной ритуальной «нагрузки». При этом общий смысл можно трактовать ещё более широко как ценность брака и обязательность в данном вопросе подчинения воле родителей и будущего мужа.

Показательна в этом отношении и лирическая песня «Ах ты, степь широкая» [16].

Ах ты, степь широкая,

Степь раздольная,

Широко ты, матушка,

Протянулася!

Ой, да не степной орёл

Подымается, -

То донской казак

Разгуляется!

Ой, да не летай, орёл,

Близко ко земле,

Ой, да не гуляй, казак,

Близко к берегу!

В ней использованы образы символы степи, орла, реки. Степь, как и долина, может символизировать человеческую жизнь. Берег подразумевает воду (чаще - реку). Про образы воды и реки мы писали выше, не будем здесь повторяться. Орёл - один из наиболее универсальных символов в фольклорах разных народов. Его связывают и с тотемическими представлениями, и мифами о возникновении (добывании) огня, и со знаками смерти и, одновременно, с бессмертием, со способностью оживления (возвращения в мир живых) ге- 
роев, и с жертвоприношениями, и с воплощением силы и могущества, и с образами «чужого», и пр. Таким образом, полисемантическое насыщение художественного образа позволяет увидеть его как многогранный символ, расшифровка которого будет зависеть от контекста, и от самого «расшифровщика»: его опыта, ценностей, готовности к пониманию символов и т.д. В данном случае мы можем говорить о смысле песни как размышлении о судьбе казака (как собирательного образа, конечно же), который постоянно находится на грани между, собственно, жизнью и смертью в силу своего социального положения (военное сословие), его мощи, силе, готовности принести свою жизнь в жертву на благо Родины.

И таких примеров можно проводить бесчисленное количество [17].

Содержательно значимо и такое обстоятельство, как непосредственная данность фольклора в реальной, чувственно ощутимой бытийственности. Разумеется, такая представленность не может быть отрефлексирована в повседневном культурном сознании, но специальное обращение к этой феноменологии должно учитывать это как непреложный факт. Отчётливо проявляются такие феноменологические корни в самых, казалось бы, остроактуальных ситуациях, как реакция на самые злободневные события, чувственно затрагивающие культурное сознание аудитории социума. Разумеется, коллизии, составляющие основу этих ситуаций, преходящи, но стремление осознать их как причастных вековому течению времени, как «опознаваемых», приводит к поискам опоры на нечто уже опривыченное, имеющее «сакральный» статус неоспоримо долженствующего. Именно в этом статусе и выступает (помимо прочих) фундаментальный корпус фольклора.

Сама антропологичность, не понимаемая в пределах собственно традициональных сообществ, а видимая как одна из фундаментальных основ культурного порядка, показывает не только неустранимость фольклорно-мифологического начала в самых, казалось бы, новационных проявлениях человеческого существа, но и всякий раз (при внимательном взгляде) подтверждает своего рода архаичность (именно в антропологическом смысле) культурного сознания homo sapiens.

У традиционного фольклора в этом смысле, не всегда оцениваемом внятно, есть несомненные особенности, которые трудно переоценить. Накопленная за многие века «народная мудрость», сконцентрированная в ёмких фольклорных «формулах», образах, действах, коррелирует с самыми острыми проблемами дня сегодняшнего и предла- гает ответы, которые могут быть услышаны, к сожалению, только сведущими людьми.

Именно в этом, на наш взгляд, заключается основная проблема, связанная с вопросом современных судеб традиционного фольклора. Антропологическая глубинность значения этого незаслуженно пренебрегаемого сегодня явления сказывается уже в современности. Но логика развития мировой цивилизации, особенно в ситуациях острейших разломов, свидетелями (и участниками) которых мы волей или неволей становимся, свидетельствует о том, что подобное пренебрежение к феномену человеческой культуры, вобравшему в себя и «архетипические», присущие любой культуре ценности и образы и, в то же время, воплотившие уникальные черты, свойственные каждой особенной культуре, чревато потерей некоторого общекультурного кода, который может найти интонацию взаимодоверия, взаимопонимания и, в конце концов, к сосуществованию на взаимоприемлемых основах.

Подтверждением этому могут служить сюжеты, образы, хранящиеся в исторической памяти традиционного фольклора, на первый взгляд, архаичные, но на деле отчётливо передающие черты сложных современных коллизий и, более того, включающие пути разрешения их. Из множества примеров мы можем обратиться, хотя бы, к книге Сулхан-Саба Орбелиани «Мудрость вымысла», авторскому тексту, но построенному, несомненно, на фольклорных основаниях. В ней содержатся притчи, которые, в том числе, созвучны современности. Так, в притче «Лиса и Козёл» [18] рассказывается о том, как Лиса и Козёл делили совместно выращенное зерно. Не сумев договориться, Лиса позвала на помощь «дядю» - Волка, а Козёл своих родственников - собак, которые разделались и с Лисой, и с Волком. Эта притча отчётливо показывает, что в случаях острых конфликтов нужно быть разборчивым в выборе союзников. Тем более тогда, когда речь идёт о жизни и смерти. Современные события дают множество примеров тому, что смысл «архаичной» притчи актуален и сегодня. Но, если в «архаическом» прошлом решение было найдено, то в современности аналогичное противостояние продолжается. Повторим, что мы не видим подобнее фольклорные образы и сюжеты как основное средство решения современных сложных ситуаций. Но включение и грамотное использование сокровищницы народной мудрости мастерами современных коммуникаций, несомненно, может способствовать хотя бы некоторому оздоровлению многих напряжённых ситуаций, которые с необходимостью ждут своего разрешения. 
Однако этим не ограничиваются антропологически фундированные черты традиционного фольклора, сохраняющего, как ни парадоксально, живое, но не всегда рефлексируемое присутствие в современной культурной среде.

В традиционном фольклоре содержатся мироустанавливающие константы, выработанные тысячелетиями, т.е. то, что принято называть культурными универсалиями: отношение к старшим, материнству, мужеству и мн. др. При этом в рамках конкретной культуры их содержание специфицируется, в том числе, в традиционном фольклоре, прежде всего, через символы. В том то и высокая потенциальность традиционного фольклора, что культурные универсалии заложены в нём изначально и неустранимы по определению. Следовательно, они не теряют значение и в современности. Так, например, трансцендентность, отчётливо проявленная и воплощённая в традиционном фольклоре (параллельные миры, духи, обращение к божествам и пр.), в современной культуре чрезвычайно актуальна как в прагматическом, так и в других, вплоть до мистических смыслов.

Наглядно мы можем увидеть это в современных практиках массовой культуры, которая генетически восходит к традиционному фольклору, органично возникла, питаясь фольклорной культурой, и напрямую использует образность и сюжетику фольклора как первоисточника. Однако, несмотря на такое родство, возникает некоторое противоречие между основательностью и глубинностью самого традиционного фольклора и некоторой поверхностностью и сиюминутностью массовой культуры. Массовая культура не обладает в той же мере смысловой интенсивностью и полинасыщенностью, капитальностью, длительной культурно-исторической «протяжённостью», что и традиционный фольклор, и, к сожалению (и к счастью - одновременно и в большей степени), не способна его полноценно заменить. То обстоятельство, что она претендует на частичное функциональное «замещение» традиционного фольклора, объективно приводит к активной эксплуатации ею фольклорных сюжетов, образов, стилистик. Однако установка на сиюминутность и специализированный характер производства массовой культуры в значительной мере выхолащивают смысловое содержание заимствованных и переработанных в ходе подобной эксплуатации фольклорных форм, текстов. Массовая культура переняла у традиционного фольклора апелляцию к антропологически чувствительным зонам культурного сознания человека и общества. Приведём лишь один из многочисленных примеров: сказка Ш. Перро «Золушка».
Опять-таки, хоть мы и обращаемся к авторскому тексту, но он, несомненно, основан на фольклорных мотивах. Следует отметить, что сюжет о девушке, в силу обстоятельств терпящей какие-либо неудобства и лишения в жизни, но в результате оказывающейся вознагражденной за это и достигшей счастья, известен в фольклорных текстах (как Европы, так и Азии) ещё до н.э. Считается, что схожий сюжет принадлежал и Эзопу, а первым авторским европейским её аналогом была сказка Дж. Базиле о Зезолле. И современная массовая культура не преминула воспользоваться данным сюжетом. Стоит указать на фильмы «Принцесса на бобах» (режиссёра В. Новака) и «Красотка» (режиссера Г. Маршалла; где даже есть прямое упоминание о сказке «Золушка»). В первом случае возникает ещё и прямая аналогия названия с наименованием сказки «Принцесса на горошине». Но не случайно «горошина», сослужившая добрую роль в сказке, послужившая катализатором правды и справедливости, заменена на «бобы», отсылая нас к фразеологизму «Остаться на бобах» (т.е. ни с чем), как бы предвосхищая финал фильма. И в том, и в другом случае женщине из бедной семьи выпадает шанс изменить свою жизнь, каждая им по-своему распоряжается. Примечательна и разница в финалах: в первом случае героиня делает выбор в пользу прежней жизни (тут можно указать на множество сказочных сюжетов, где героиня остаётся при своих интересах, например, «Лисичка со скалочкой»), а во втором - в пользу новой, богатой и счастливой. Этот простейший пример показывает, что сюжеты традиционного фольклоpa, его образы активно используются массовой культурой, перерабатываются, осовремениваются. При этом фольклор не теряет своего актуального звучания, даже в условиях его крайне примитивизированной подачи, упрощения, обеднения образов и символов. Наоборот, «...фольклор в условиях массовой культуры транслирует базовые философскокультурологические ценности (Мир, Дом, Семья, Человек), воплощённые во множестве архетипических образов и выступающие в качестве смысло-содержательных доминант современного медиапространства, в частности, масс-медиа (телевидение, радио, печатные средства, Интернет, сеть, реклама, кино, видео, фото, анимация и пр.)» $[19$, с. 8]. Эти базовые ценности и есть культурные универсалии, о которых мы говорили ранее. Следовательно, в современной культуре традиционный фольклор выполняет значимую и уникальную по характеру роль в полифоническом звучании сложной современной культуры.

Тем самым культур-антропологические основания традиционного фольклора предстают перед 
нами в своих культурогенных, остроактуальных свойствах. Вопрос в том, найдутся ли люди, способные применить этот потенциал с тем, чтобы хотя бы отчасти оздоровить современную социокультурную среду. Разумеется, современная культура сложным образом соотносится со своими архаическими корнями. Поэтому для распознания подобных архаичных звучаний, реально бытийствующих, требуется особая исследовательская оптика. В калейдоскопе, бесконечно варьирующем очевидные явления, необходимо видеть не только остро актуальные коллизии, но и их традициональные основания.

Конечно, с первого взгляда трудно распознать звучания традиционного фольклора в этих, иной раз причудливых вариациях. Вместе с тем следует отчётливо понимать, что в этом, казалось бы, пестром спектре проявлений культурной активности воплощается феноменологическая основа, возникшая, сконденсированная и далее воспроизводимая в этих вариациях смысловая сущность вековой народной мудрости, присущей традиционному фольклору. Этот тезис находит своё подтверждение даже в таких, на первый взгляд, маргинальных нашей проблематике явлениях, как современный социо-политический интернетовский нео-новояз. В ожесточённой полемике, разворачивающейся, в том числе, в блоггерском пространстве, мы видим инстинктивное обращение авторов посланий к тем же самым корневым фольклорным кодам, которые в значительной мере составляют формульный корпус традиционного фольклора. Сама лексика, метафорические тропы, спецификация выразительных средств этих сообщений отчётливо демонстрируют неосознаваемую, но легко прочитываемую связь с механизмами, органично свойственными именно традиционному фольклору.
Так, например, вполне очевидно демонстрируют это такие новообразования, как «вышиватники» (от соединения ватник и вышиванка; в прямом значении - те, кто готов носить и ту, и другую одежду; в смысловом - те, кто готов принять одновременно позицию разных стран), «колорады» (пренебрежительное отношение к гражданам, носящим Георгиевскую ленту), «диванные войска» (те, кто ведёт «бои», как правило, в пространстве Интернета), «бонденок» (ребёнок исполнителя роли Джеймса Бонда), и мн. др. Несомненно, что природа такого нео-новояза напрямую соотносится с языковой игрой, а, следовательно, со «скоморошьей», карнавальной культурой, что напрямую отсылает нас к фольклорным практикам прошлого, не потерявшим своего актуального звучания в современности.

Разумеется, это сугубо частный пример того, как корневые основы механизмов и ценностно-смысловых фундаменталий традиционного фольклора, пусть в самых причудливых формах, демонстрируют органическую связь с первичными антропологическими универсалиями, которые были присущи фольклору в начале его генезиса, сопровождали его на протяжении существования, и являют себя сегодня, пусть не всегда отчётливо узнаваемо.

Все это ещё раз заставляет нас с большим вниманием обратиться к теме традиционного фольклора не как к архаичному явлению, а как к части субстанциальной среды современного, актуального, остро злободневного бытия человечества и как целого, и как сложного соотношения народов, этносов, государств и субкультур. В этом и проявляется специфичность и укорененность глубинных бытийственых черт в актуальных состояниях антропологических констант традиционного фольклора в современной культуре.

\section{Список литературы:}

1. Хакимов А. Фольклор и традиционная культура. URL: http://sanat2013.orexca.com/rus/archive/1-01/akbar_khakimov. shtml (дата обращения 25.10.2015).

2. Татаринова Т.Л. Эволюция и инволюция жанров музыкального фольклора на примере эпоса и обрядовых песен // Дом Бурганова. Пространство культуры. 2015. № 3. С. 202-207.

3. Флиер А.Я. Современная культура как тенденция // Знание. Понимание. Умение. 2012. № 1. URL: http://www.zpujournal.ru/e-zpu/2012/1/Flier_Contemporary-Culture/ (дата обращения 27.10.2015).

4. Седухин Б.В. Народная музыкальная культура: состояние и тенденции развития: Дис. ... канд. культурологии. М., 2004. $131 \mathrm{c.}$

5. Варламов Д. Народные традиции в контексте эволюции национального инструментализма в музыкальном искусстве России XIX-XX веков: Автореф. дис. ... докт. искусствоведения. Саратов, 2009. 339 с.: ил.

6. Куц В.А. Культурная идентичность как способ реализации защитных функций культуры // Культура культуры: электронный журнал. 2015. URL: http://cult-cult.ru/cultural-identity-as-a-way-of-realization-of-protective-functions-ofculture/ (дата обращения 28.10.2015).

7. Консон Г.Р. Метод целостного анализа художественных текстов. М.: Книга по Требованию, 2012. 419 с.

8. Гуревич П.С. Философия культуры: учебник для высшей школы. M.: Nota Bene, 2001. 352 c.

9. Каминская Е.А. К спорам об определении термина «фольклор» // Шестые Лазаревские чтения «Лики традиционной культуры начала XXI столетия»: материалы международной научной конференции. Челябинск, 26-27.02.2013. С. 282-285.

10. Круглый стол «Что такое фольклор?» (навстречу первому всероссийскому конгрессу фольклористов) // Традиционная культура. 2005. № 2, 3, 4 . 
11. Путилов Б.Н. Фольклор и народная культура / Отв. ред. А.С. Мыльников. СПб.: Наука, 1994. 239 с.

12. Фундаментальная электронная библиотека: «Русская литература и фольклор». URL: http://feb-web.ru/feb/litenc/ encyclop/leb/leb-7751.htm (дата обращения 15.12.2012).

13. Спирова Э.М. Универсальный язык глобалистики // Век глобализации. 2012. № 1. С. 34-45.

14. Неклюдов С.Ю. К вопросу о фольклоре и обряде // Миф, символ, ритуал. Народы Сибири. [Сб. статей в честь Е.С. Новик.] М.: РГГУ. 2008. C. 11-22. URL: http://www.ruthenia.ru/folklore/neckludov33.htm.

15. Хоменко В.Л. Народные песни Челябинской области: метод. рек. для руководителей самодеятельных хоров народной песни. Челябинск, 1980.60 с.

16. Ах ты, степь широкая. URL: http://pesni.retroportal.ru/np1/03.shtml (дата обращения 27.11.2015).

17. Каминская Е.А. Механизмы выявления культурных смыслов традиционного фольклора // Вестник славянских культур. 2014. № 33. С. 77-89.

18. Сулхан-Саба Орбелиани. Мудрость вымысла. URL: http://lukianpovorotov.narod.ru/Orbeliani_Mudrost_vymysla.htm (дата обращения 20.11.2015).

19. Зенин С.Н. Традиционный словесный фольклор и масс-медиа: тенденции взаимодействия в современном пространстве: Автореф. дис. ... канд. филос. наук. Белгород, 2009. 23 с.

20. Хренов Н.А. Модернизационные процессы на рубеже XX-XXI веков и судьба традиционных ценностей // Культура и искусство. 2013. № 5. С. 544-555. DOI: 10.7256/2222-1956.2013.5.9570.

21. Семченко О.А. Международный форум «Традиционная культура как стратегический ресурс устойчивого развития общества» (17-20 апреля 2012 г.; Могилев, Республика Беларусь) // Культура и искусство. 2012. № 4. С. $109-110$.

22. Любимова Т.Б. Что передается в традиции? // Культура и искусство. 2014. № 5. C. 501-513. DOI: 10.7256/22221956.2014.5.12587.

23. Спирова Э.М. Символика жизни и смерти // Психология и психотехника. 2010. № 5. С. 75-82.

\section{References (transliterated):}

1. Khakimov A. Fol'klor i traditsionnaya kul'tura. URL: http://sanat2013.orexca.com/rus/archive/1-01/akbar_khakimov. shtml (data obrashcheniya 25.10.2015).

2. Tatarinova T.L. Evolyutsiya i involyutsiya zhanrov muzykal'nogo fol'klora na primere eposa i obryadovykh pesen // Dom Burganova. Prostranstvo kul'tury. 2015. № 3. S. 202-207.

3. Flier A.Ya. Sovremennaya kul'tura kak tendentsiya // Znanie. Ponimanie. Umenie. 2012. № 1. URL: http://www.zpu-journal. ru/e-zpu/2012/1/Flier_Contemporary-Culture/ (data obrashcheniya 27.10.2015).

4. Sedukhin B.V. Narodnaya muzykal'naya kul'tura: sostoyanie i tendentsii razvitiya: Dis. ... kand. kul'turologii. M., $2004.131 \mathrm{~s}$.

5. Varlamov D. Narodnye traditsii v kontekste evolyutsii natsional'nogo instrumentalizma v muzykal'nom iskusstve Rossii XIX-XX vekov: Avtoref. dis. ... dokt. iskusstvovedeniya. Saratov, 2009. 339 s.: il.

6. Kuts V.A. Kul'turnaya identichnost' kak sposob realizatsii zashchitnykh funktsii kul'tury // Kul'tura kul'tury: elektronnyi zhurnal. 2015. URL: http://cult-cult.ru/cultural-identity-as-a-way-of-realization-of-protective-functions-of-culture / (data obrashcheniya 28.10.2015).

7. Konson G.R. Metod tselostnogo analiza khudozhestvennykh tekstov. M.: Kniga po Trebovaniyu, 2012. 419 s.

8. Gurevich P.S. Filosofiya kul'tury: uchebnik dlya vysshei shkoly. M.: Nota Bene, 2001. 352 s.

9. Kaminskaya E.A. K sporam ob opredelenii termina «fol'klor» // Shestye Lazarevskie chteniya «Liki traditsionnoi kul'tury nachala XXI stoletiya: materialy mezhdunarodnoi nauchnoi konferentsii. Chelyabinsk, 26-27.02.2013. S. 282-285.

10. Kruglyi stol «Chto takoe fol'klor?» (navstrechu pervomu vserossiiskomu kongressu fol'kloristov) // Traditsionnaya kul'tura. 2005. № 2, 3, 4.

11. Putilov B.N. Fol'klor i narodnaya kul'tura / Otv. red. A.S. Myl'nikov. SPb.: Nauka, 1994. 239 s.

12. Fundamental'naya elektronnaya biblioteka: «Russkaya literatura i fol'klor». URL: http://feb-web.ru/feb/litenc/encyclop/ leb/leb-7751.htm (data obrashcheniya 15.12.2012).

13. Spirova E.M. Universal'nyi yazyk globalistiki // Vek globalizatsii. 2012. № 1. S. 34-45.

14. Neklyudov S.Yu. K voprosu o fol'klore i obryade // Mif, simvol, ritual. Narody Sibiri. [Sb. statei v chest' E.S. Novik.] M.: RGGU, 2008. S. 11-22. URL: http://www.ruthenia.ru/folklore/neckludov33.htm.

15. Khomenko V.L. Narodnye pesni Chelyabinskoi oblasti: metod. rek. dlya rukovoditelei samodeyatel'nykh khorov narodnoi pesni. Chelyabinsk, $1980.60 \mathrm{~s}$.

16. Akh ty, step' shirokaya. URL: http://pesni.retroportal.ru/np1/03.shtml (data obrashcheniya 27.11.2015).

17. Kaminskaya E.A. Mekhanizmy vyyavleniya kul'turnykh smyslov traditsionnogo fol'klora // Vestnik slavyanskikh kul'tur. 2014. № 33. S. 77-89.

18. Sulkhan-Saba Orbeliani. Mudrost' vymysla. URL: http://lukianpovorotov.narod.ru/Orbeliani_Mudrost_vymysla.htm (data obrashcheniya 20.11.2015).

19. Zenin S.N. Traditsionnyi slovesnyi fol'klor i mass-media: tendentsii vzaimodeistviya v sovremennom prostranstve: Avtoref. dis. ... kand. filos. nauk. Belgorod, 2009. $23 \mathrm{~s}$.

20. Khrenov N.A. Modernizatsionnye protsessy na rubezhe XX-XXI vekov i sud'ba traditsionnykh tsennostei // Kul'tura i iskusstvo. 2013. № 5. S. 544-555. DOI: 10.7256/2222-1956.2013.5.9570.

21. Semchenko O.A. Mezhdunarodnyi forum «Traditsionnaya kul'tura kak strategicheskii resurs ustoichivogo razvitiya obshchestva» (17-20 aprelya 2012 g.; Mogilev, Respublika Belarus') // Kul'tura i iskusstvo. 2012. № 4. S. 109-110.

22. Lyubimova T.B. Chto peredaetsya v traditsii? // Kul'tura i iskusstvo. 2014. № 5. S. 501-513. DOI: 10.7256/22221956.2014.5.12587.

23. Spirova E.M. Simvolika zhizni i smerti // Psikhologiya i psikhotekhnika. 2010. № 5. S. 75-82. 